\title{
DETECTION OF GRINDING BURN THROUGH THE HIGH AND LOW FREQUENCY BARKHAUSEN NOISE
}

\author{
Anna Mičietová, Miroslav Neslušan, Robert Čep, Vladislav Ochodek, Branislav Mičieta, Marek Pagáč
}

Original scientific paper

This paper deals with detection of surface damage after grinding through non-destructive micro magnetic technique based on Barkhausen noise. Paper compares the high and low frequency techniques and their sensitivity to detect surface burn and thickness of heat affected zone. The results of investigation indicate that the low frequency technique can more clearly detect surface burn than the high frequency technique due to relatively high thickness of heat affected zones obtained after grinding operations. The paper also discusses additional aspects of micro magnetic testing as a multi parametric technique where such parameters as Peak Position of Barkhausen noise loop correlate with the thermal load of machined surface. The paper also reports about corresponding structure transformations and associated stress state beneath the surface.

Keywords: Barkhausen noise; detection; grinding; surface burn

Otkrivanje brusne opekline putem visoke i niske frekvencije Barkhausenovog šuma

Izvorni znanstveni članak

Rad razmatra pojavu oštećenja površine nakon brušenja putem nedestruktivnog mikro magnetskog načina rada temeljenog na Barkhausenovom šumu. Uspoređuju se metode visoke i niske frekvencije i njihova osjetljivost u otkrivanju površinske opekline i debljine zone pod utjecajem topline. Rezultati istraživanja pokazuju da se metodom niske frekvencije može jasnije otkriti površinska opeklina nego metodom visoke frekvencije zbog relativno velike debljine zona pod utjecajem topline nastalih nekon brušenja. U radu se također raspravlja o dodatnim aspektima mikro magnetskog ispitivanja kao multi parametrijske metode u kojoj su parametri kao što je vršni položaj petlje Barkhausenovog šuma u korelaciji s toplinskim opterećenjem obrađivane površine. U radu se također daju odgovarajuće promjene u strukturi i s tim povezano naprezanje ispod površine.

Ključne riječi: Barkhausenov šum; brušenje; otkrivanje; površinska opeklina

\section{Introduction}

Magnetization in a ferromagnetic material is due to the nucleation and reconfiguration of domains which result from the motion of magnetic domains and corresponding Bloch Walls (BW). Motion of BW and domains is usually pinned by precipitates and other lattice defects and results in their discontinuous movement. Then pulsating magnetization can be obtained and the corresponding discontinuous jumps of the BW occur. This phenomenon is named Barkhausen noise [1]. This technique is mostly adopted for inspection of ground surfaces since strong correlation between the heat generated in the grinding wheel - workpiece contact associated surface burn and the corresponding $\mathrm{BN}$ values. Capability of BN technique considering the reliable and very sensitive detection of grinding burn results from thermal softening of the surface as well as subsurface layers and stress state. It is well known that the surface of high hardness gives the poor $\mathrm{BN}$ values whereas softer structures emit higher BN values. Further, magneto elastic responses are suppressed when compressive stresses occur while more pronounced $\mathrm{BN}$ values can be detected for the surface containing mainly tensile stresses due to increasing domains parallel with the direction of magnetic field (while the domains perpendicular to the load are decreasing) [2, 3].

The main advantages of $(\mathrm{BN})$ method are associated with very fast surface response (in seconds), portability of $\mathrm{BN}$ systems and ability to be easily integrated into automatic cycles. BN techniques are mainly applied for monitoring surface integrity of parts loaded near their physical limits. Then surface integrity expressed in terms of residual stresses, hardness alterations or structure transformation is correlated with $\mathrm{BN}$ values obtained from surface as well as associated functionality of produced parts $[4,5]$. Bearings are usually critical components in machines structures made of hardened steels. Grinding operations usually take a major role when final operations are performed. Thermally induced damage during grinding is mainly a function of wheel wear, cutting conditions and cutting fluid $[6,7]$. The role of $\mathrm{BN}$ technique is usually connected with variable surface integrity despite the constant cutting and other conditions being kept constant. Acceptable cutting conditions, grinding wheel, its dressing, coolant supply and other conditions are usually properly suggested to obtain the acceptable precision of produced parts and required surface integrity $[8,9]$. It should be understood that grinding process itself is affected by many parameters; these parameters can randomly vary with more or less pronounced influence on grinding process. Therefore, quality of production can vary and surface integrity of certain parts can be indicated as unacceptable. Being so, industrial relevance for micromagnetic evaluation of surface integrity is connected with detection of thermally damaged surfaces after grinding $[10,11,12]$ as a phenomenon randomly occurring in production. Information about surface integrity then can be used for detection and understanding of critical aspects of grinding as well as possible optimization concepts.

$\mathrm{BN}$ responses depend on many parameters such as magnetizing frequency, magnetizing voltage, sensor shape, etc. Therefore, when a proper concept for surface detection is suggested many aspects should be taken into consideration to meet the specific requirements of monitoring technique and attain obtainable sensitivity. This study is mainly focused on evaluation of surface integrity after grinding with variable grinding wheel wear. Two different high and low frequency $\mathrm{BN}$ techniques are 
compared and sensitivity of both concepts is discussed. The high frequency technique has found the high industrial relevance for monitoring ground surfaces after finishing grinding when the final state of surface is produced at low removal rates [12]. The high infeed rates are usually employed for roughing cycles during grinding. At one hand, such grinding does not produce the final state of surface. On the other hand, surface damage during roughing can penetrate quite deep beneath the free surface. In some cases thickness of damaged layer can exceed the thickness of the layer removed during the consecutive finishing cycles. Being so, rough grinding can significantly affect surface integrity despite correctly performed final stages of grinding cycle.

\section{Experimental conditions}

The experimental study was carried out on hardened steel $100 \mathrm{Cr} 6$ of hardness varying between $60 \div 62 \mathrm{HRC}$ $55 \mathrm{~mm}$ in external diameter, $41 \mathrm{~mm}$ in internal diameter and $30 \mathrm{~mm}$ in width. 27 rings were subsequently ground under the conditions indicated in Tab. 1 as a long term test to initiate the progressive grinding wheel wear. Cutting time (45 seconds) for each ring was kept constant whereas grinding wheel was not redressed after each ring to accumulate the wheel wear (grains wear) due to long term and repetitive interaction of the grinding wheel surface with the step by step ground rings.

Table 1 Experimental conditions during grinding

\begin{tabular}{|l|l|}
\hline Grinding wheel & $01350 \times 50 \times 127$, A98 $80 \mathrm{~J} 9 \mathrm{~V}$ \\
\hline Cutting condition & $\begin{array}{l}v_{\mathrm{c}}=25 \mathrm{~m} / \mathrm{s}, v_{\mathrm{f}}=11 \mathrm{~m} / \mathrm{min}, v_{\mathrm{p}}=0,015 \\
\mathrm{~mm} / \mathrm{s}, \text { total infeed } 0,3 \mathrm{~mm} \\
\text { single crystal diamond dresser, wet } \\
\text { cutting, Ecocool } 3 \%, 3 \text { spark out rev. }\end{array}$ \\
\hline Machine tool & 2uD P27 50 \\
\hline
\end{tabular}

Table 2 BN devices and associated parameters

\begin{tabular}{|l|c|c|}
\hline & Low frequency & High frequency \\
\hline \multicolumn{1}{|c|}{ Device: } & Meb2c & RollScan 300 \\
\hline Mag. frequency (Hz) & 0,5 & 125 \\
\hline Mag. voltage (V) & 10 & 10 \\
\hline Shape of mag. current & sine & sine \\
\hline $\begin{array}{l}\text { Analyzed frequencies } \\
\text { of BN (kHz) }\end{array}$ & $1 \div 50$ & $70 \div 200$ \\
\hline $\begin{array}{l}\text { Skin depth of detection } \\
(\mu \mathrm{m})\end{array}$ & $\begin{array}{c}<700 \text { (usually } \\
\text { about } 150)\end{array}$ & $20 \div 100$ \\
\hline $\begin{array}{l}\text { Max. mag. field } \\
\text { strength (Gauss) }\end{array}$ & $400[10,11]$ & $80[10,11]$ \\
\hline Measured points & 8 & 8 \\
\hline
\end{tabular}

Micromagnetic testing was performed by the use of two different $\mathrm{BN}$ devices indicated in Tab. 2. BN measurements and corresponding metallographic observations were carried out in the centre of a ring width. Residual stresses were measured by mechanical method when surface containing residual stresses is electrolytic etched and associated deformation due to removed stresses is simultaneously measured.

\section{Low frequency Barkhausen noise}

It should be noticed that the surface inspection of ground surfaces was carried out via two different $\mathrm{BN}$ devices (high and low frequency) of different design, producer as well as software package and corresponding magnetoelastic signal processing. $\mathrm{BN}$ values obtained from the low frequency system Meb2c represent the area of envelope curves (as shown in Fig. 1) whereas BN values extracted from the high frequency device RollScan represent RMS values of a received magneto elastic signal oscillation (see Fig. 8). Nevertheless, both systems indicate the same physical quantity. Substantial and valuable difference can be viewed in the analysed frequency range.

Fig. 1 shows that gradual grinding wheel wear (and corresponding alteration of grinding grain shape) dramatically affects surface integrity expressed in terms of envelope shape and corresponding $\mathrm{BN}$ values indicated in Fig. 2. While the low BN values are obtained in the initial phases of grinding process with reduced thermal softening, progressive intensification of friction processes in the wheel - workpiece contact induces increasing grinding forces which in turn transform to heat penetrating deeper beneath the free surface. For this reason, the ground surface is exposed to the higher degree of thermal softening and abrupt increase of the corresponding $\mathrm{BN}$ values. An additional characteristic sign of surface damage can be also viewed. As shown in Fig. 1 the low envelope areas, their low amplitudes and the typical smooth envelopes can be obtained for surfaces with the low thickness of heat affected zone (HAZ) whereas more pronounced envelope oscillation is usually detected when high amplitudes and associated envelope areas are found.

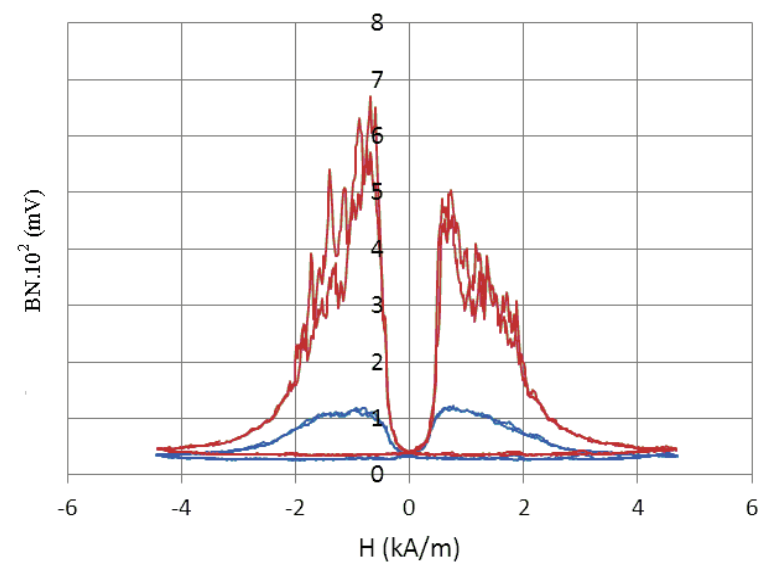

Figure 1 Envelope curves of BN, low frequency technique, Meb2c, red envelope - ring n.14, blue envelope - ring n.1

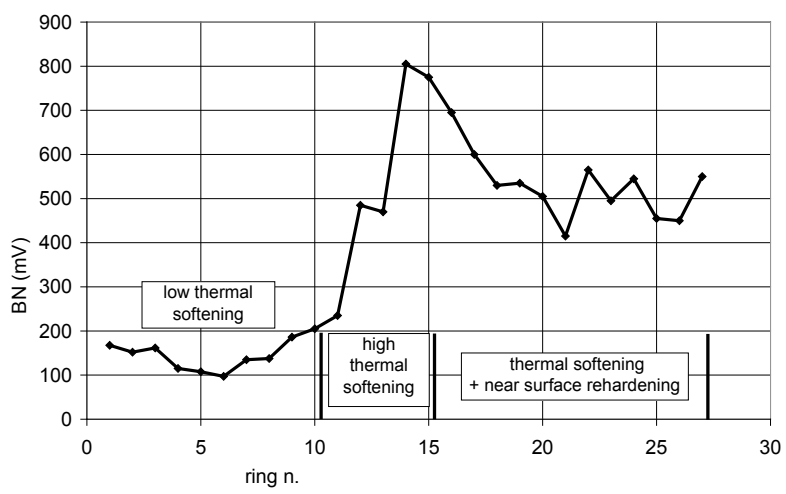

Figure 2 Influence of grinding wheel wear on the area of BN envelopes, low frequency technique, Meb2c 


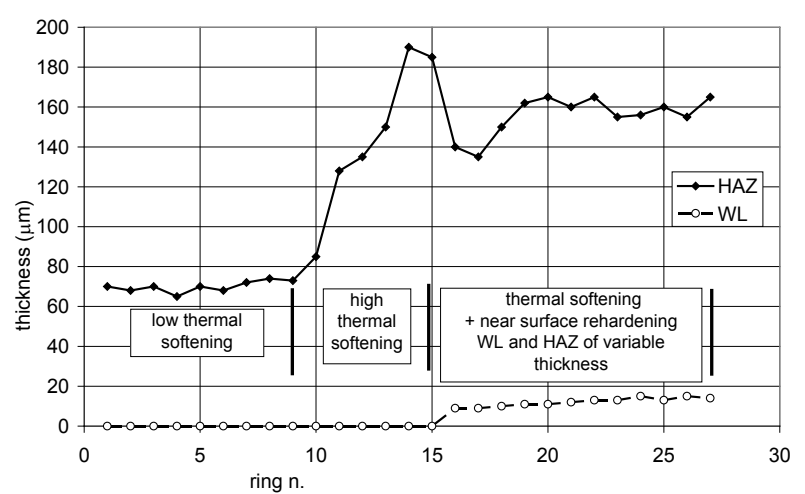

Figure 3 Influence of grinding wheel wear on thickness of (HAZ) and white layers (WL)

As stated above, progressive long term wheel workpiece contact causes the progressive grain shape transformation, associated intensification of friction, increase in grinding forces expressed in terms of their static and dynamic values (process dynamics) and corresponding heat generation. Then higher temperatures in the grinding wheel - workpiece contact are assumed together with deeper penetration of produced heat causing extending thickness of HAZ. Being so, thermal softening occurs in the deeper layer except the near surface where more pronounced thermal softening can be assumed due to increasing thermal load of ground surface.

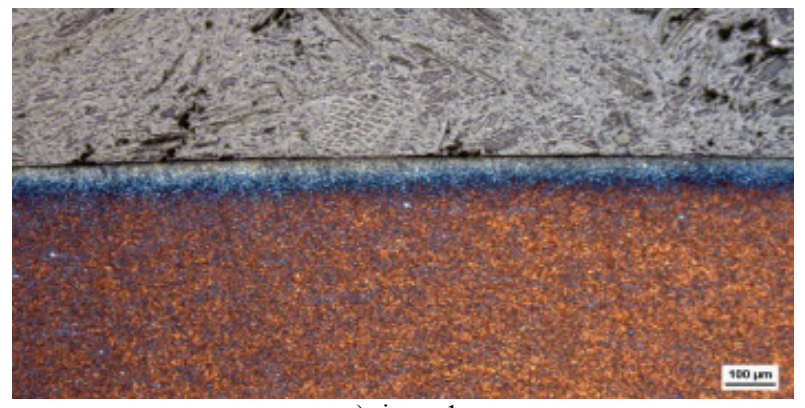

a) ring n.1

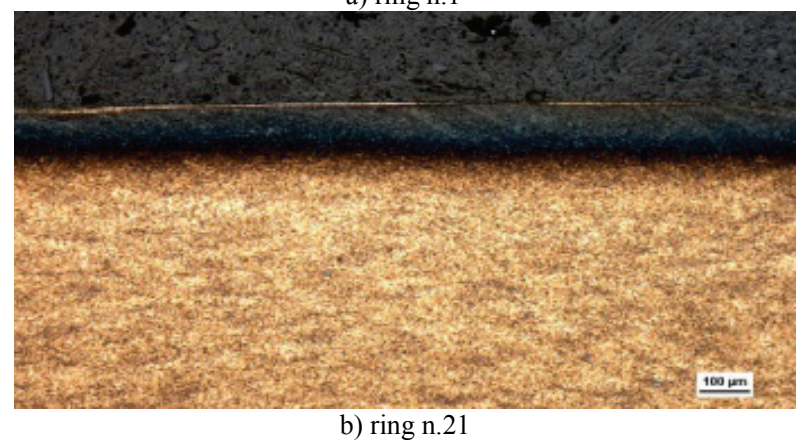

Figure 4 Microstructure of surface after grinding

It is well known that $\mathrm{BN}$ values depend on $\mathrm{BW}$ motion (average of BW motion paths) as well as BW arrangement. BW interferes with microstructural features such as dislocation, precipitates, grain boundaries, other phases and lattice imperfections as well as magnitude and nature of residual stresses. Moorthy et al. [10, 11] reported that microstructural features affect the pinning strength and the mean free path of the BW displacement while stresses affect mainly domain alignment with respect to the stress direction. Variation in microstructure and stress state alters magneto elastic responses during cyclic magnetization. Explanation of higher $\mathrm{BN}$ values with the progressive grinding wheel wear is connected with the more pronounced thermal softening influencing microstructure and stress state in a synergistic manner. When limited thermal load of ground surface is assumed, the microstructure is dominated by the carbide precipitates and the paramagnetic retained austenite phase, which can be considered as strong obstacles for BW motion. In addition, BW also interferes with the high dislocation density. As soon as the more pronounced thermal softening takes place BW movement is enhanced due to reduced dislocation density, coarsening of carbide precipitates and transformation of paramagnetic austenite to martensite. Being so, thermal softening induced by grinding strongly correlates with $\mathrm{BN}$ values (see Fig. 2) as well as increasing HAZ thickness as Figs. 2, 3 and 4 indicate. Furthermore, residual stresses shifted towards the tensile zone also contribute to the higher level of generated BN (see Fig. 13). It is also worth to mention that thickness of HAZ (see Fig. 3) - especially for more developed grinding wheel wear - could exceed the thickness of layer usually removed during the finishing grinding. Thus the rough grinding cycles can remarkably affect the BN responses of produced components despite well preformed finishing grinding.

Fig. 2 indicates that after abrupt increase of $\mathrm{BN}$ values (corresponding with increasing thermal surface softening) a certain BN fall can be found in the transition zone where increasing thermal softening and corresponding $\mathrm{BN}$ values occur. $\mathrm{BN}$ values reach the maximum about $800 \mathrm{mV}$, then drop down and oscillate at level around $500 \mathrm{mV}$. This decrease strongly correlates with lower thickness of HAZ obtained in the final phases of grinding process together with discontinuous white layer (WL) of variable thickness found on the ground surfaces as shown in Fig. $4 \mathrm{~b}$ a Fig. 6a. Two basic phenomena contribute to reduction of magneto elastic responses obtained in the final phases of grinding process. First one is associated with occurrence of white layer (WL) near the surface as a layer containing re-hardened very fine grain structure of high dislocation density (and therefore corresponding high hardness) containing mainly compressive stresses $[13,14]$ as well as higher content of retained austenite. Second one is associated with reduced thickness of HAZ as a result of new grinding grains initiated in the wheel - workpiece contact. It is well known that self - sharpening of grinding wheel is initiated when the grinding force loading the grains attains the ultimate value which grains (respective bond) cannot afford.

It should be also pointed out that progressive grinding wheel wear is connected with increasing intensity of self - excited vibration affecting mainly homogeneity of ground surfaces expressed in $\mathrm{BN}$ values respectively its distribution around the periphery of ground surface (Fig. 5 and 7). The similar results for hard turned surfaces were previously reported [13]. Then low BN values correspond with their more homogeneous distribution whereas unstable grinding operation results with more pronounced $\mathrm{BN}$ non homogeneity as a result of variable HAZ thickness due to variable wheel - workpiece position. It should be noticed that thickness of HAZ and WL indicated in Fig. 3 represents the maximum values obtained from observed micrographs such as shown in 
Fig. 4 and Fig. 6. As Fig. 6 illustrates, relatively low and variable thickness of HAZ without WL layer can be observed as well as the thick HAZ together with thin discontinuous WL induced on the surface of the same part.

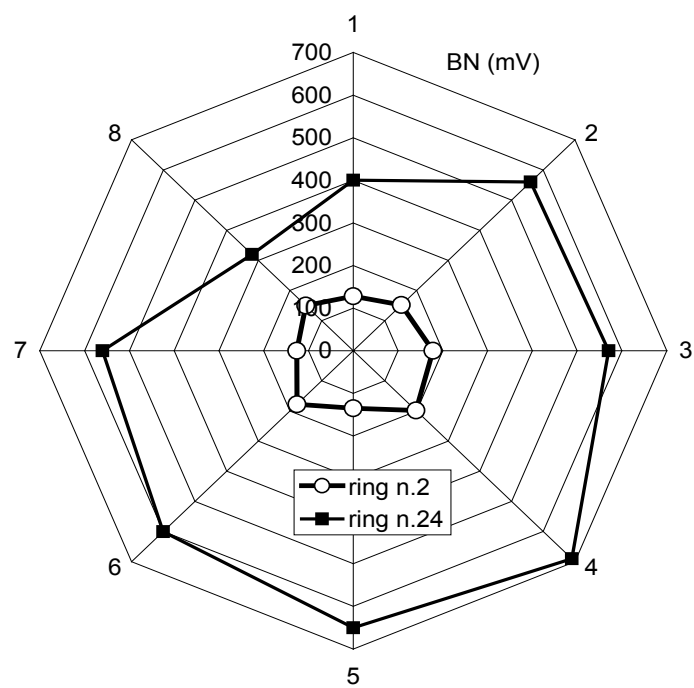

Figure 5 Distribution of $\mathrm{BN}$ around the periphery of ground rings, low frequency technique, Meb2c

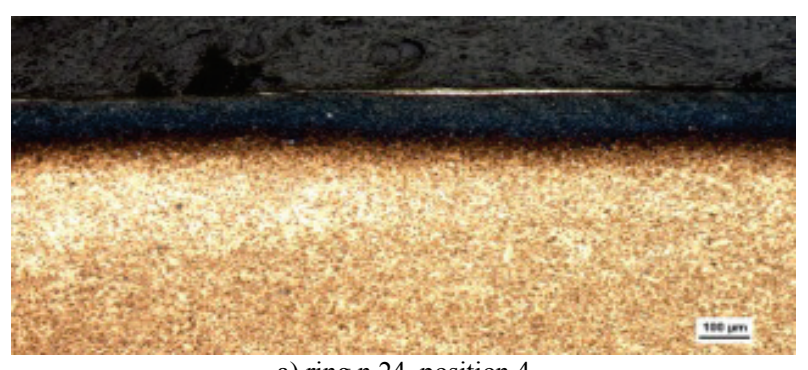

a) ring n.24, position 4

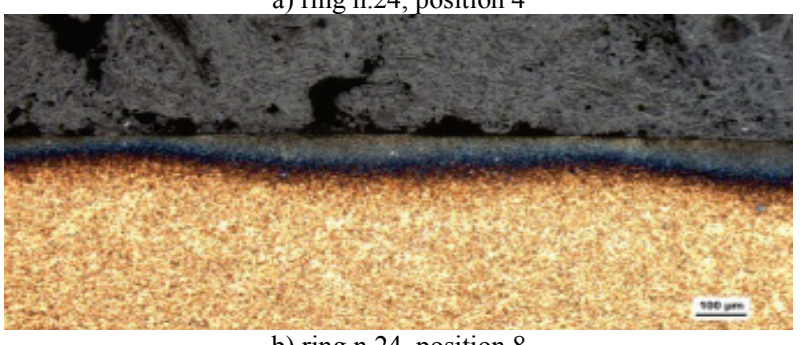

b) ring n. 24 , position 8

Figure 6 Microstructure of surface after grinding ring n.24, see also Fig. 5

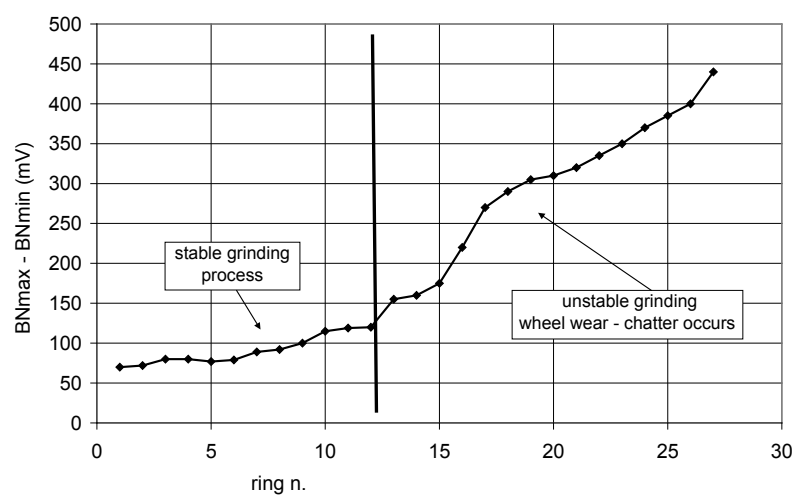

Figure 7 Range of $\mathrm{BN}$ envelopes area within ground parts, low frequency technique, Meb2c

A certain variation of surface integrity and corresponding $\mathrm{BN}$ values within a ground part should be taken into consideration when $\mathrm{BN}$ technique is adopted for monitoring surface integrity. Then a produced part should be either dynamically scanned or the concept of multiple points measurements should be incorporated. On the other hand, the low frequency $\mathrm{BN}$ technique itself exhibits sufficient sensitivity for grinding damage detection since magneto elastic responses obtained in the transient zone are up to 8 times higher than those in the initial phase of grinding process. Moreover, BN values obtained in the zone where re-hardening occurs are still 5 times higher than those after grinding wheel dressing.

\section{High frequency Barkhausen noise}

Typical BN signals obtained from the higher frequency device RollScan and software $\mu$ Scan are illustrated in Fig. 8 and 9. While the low magnitude of BN signal (Fig. 8) is obtained for surfaces with the low thermal load and corresponding low thickness of HAZ, higher magneto elastic responses in the transient zone (see Fig. 9) correlate with increasing thickness of HAZ. Overall $\mathrm{BN}$ values course through the whole grinding cycle is illustrated in Fig. 10. Compared to the low frequency technique illustrated in Fig. 2, different phases of grinding process can be also found such as initial phase associated with the low thermal load, transient zone as well as the zone in which re-hardening burn occurs.

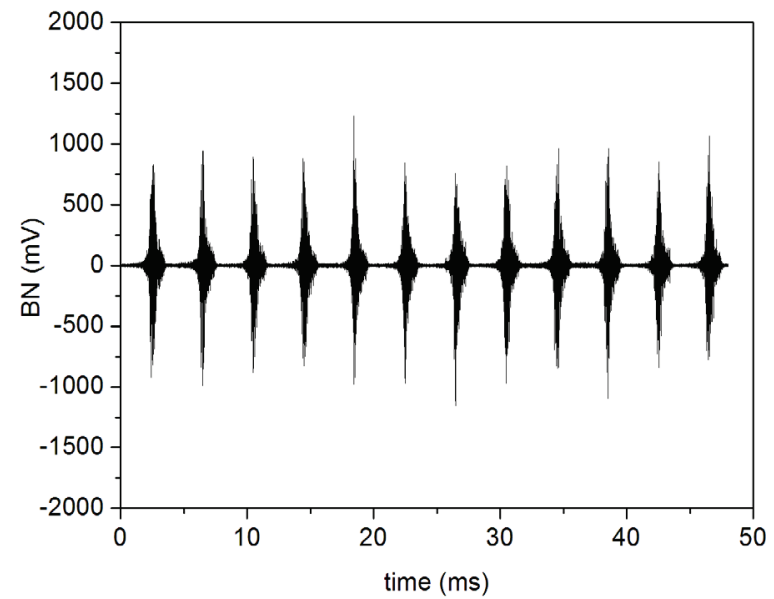

Figure 8 Record of BN signal, ring n. 2, high frequency technique, $\mu \mathrm{Scan}$

The main difference between the high and the low frequency technique employed for monitoring rough grinding should be viewed in less pronounced $\mathrm{BN}$ signal level increase in the transient zone as well as the signal decrease in the final phases of grinding cycle. Then differences between the different phases of grinding cycle expressed in terms of the high frequency $\mathrm{BN}$ values are less apparent than those obtained for the high frequency technique. Being so, evaluation of surface integrity state induced by grinding operation via the high frequency technique is less reliable in rough grinding. Although the transient zone, where structure transformation does not occur, can be easily distinguished from initial zone, nearly the same $\mathrm{BN}$ values can be obtained during the initial as well as final phases of grinding due to increasing range in which $\mathrm{BN}$ values occur. While the low $\mathrm{BN}$ values in the initial phase of grinding cycle are attributed 
to the low thermal softening, the low values indicated in the final phase are mainly connected with the existence of discontinuous WL as well as variable HAZ thickness. It can be concluded that the high frequency $\mathrm{BN}$ technique itself in this case (rough grinding) does not exhibit sufficient sensitivity for grinding damage detection since comparable magneto elastic responses can be obtained in the different phases of grinding cycle. Being so, the properly suggested high frequency concept for grinding damage detection needs either to carry out the measurement of $\mathrm{BN}$ value as a dynamic quantity (or multiple point measurement) or incorporate additional information extracted from the raw $\mathrm{BN}$ signal to distinguish between initial and final phases of grinding cycles.

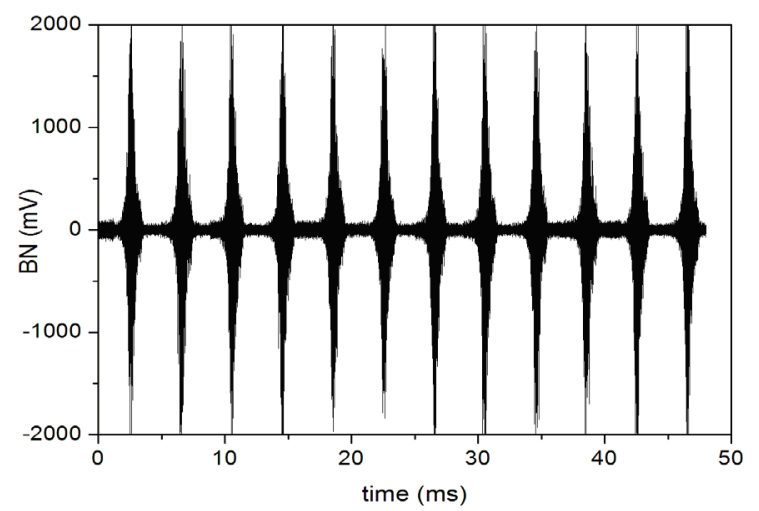

Figure 9 Record of BN signal, ring n. 13, high frequency technique, $\mu \mathrm{Scan}$

The low BN values obtained in the final phases of grinding cycle resulting from the low thickness of HAZ due to unstable grinding process are difficult to distinguish from low $\mathrm{BN}$ values obtained in the initial phases since the surfaces of the nearly same surface integrity are investigated. On the other hand, existence of WL represents structure transformation exclusively occurring in the final phase of grinding cycle. It is well known that WL induced by grinding operation consist of secondary very fine grain martensite and retained austenite.

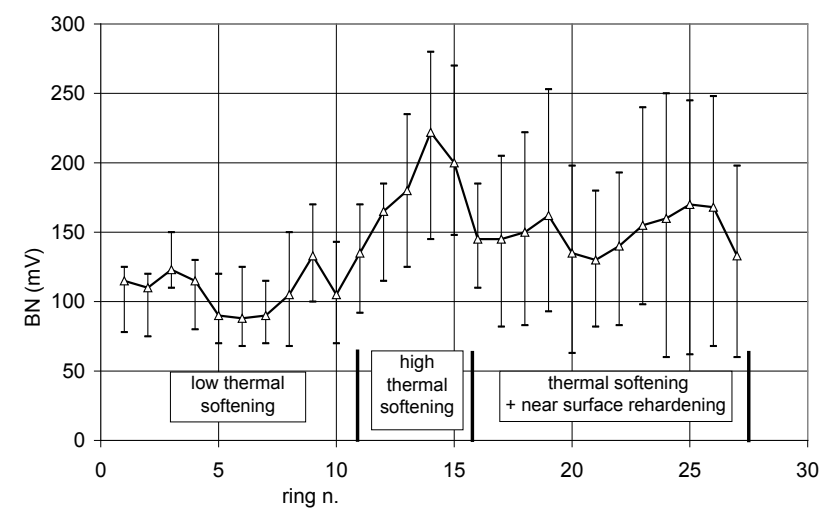

Figure 10 Influence of grinding wheel wear on BN values (RMS), high frequency technique, $\mu$ Scan

Furthermore, it was previously reported that Peak Position (indicated by Fig. 11 as a position of the curve maximum) would correspond to the average grain size and the profile would correspond to the grain size distribution $[12,15]$. It can be easily understood that the fine grain WL structure emits magneto elastic pulses of low magnitude and high frequency. Therefore, Peak Position is shifted toward higher values due to frequency spectrum alteration. Moreover, also the more developed pure thermal softening (without WL) produces the structure of higher mechanical and magnetic strength compared to that ground in the initial phase of grinding cycle, see Fig. 11. Thermal softening usually results in $\mathrm{BN}$ envelopes of lower magnetic strength and the corresponding lower Peak Position due to reduced dislocation density, transformations in the volume of retained austenite, etc. since BW interfere with all lattice defects. However, in this particular case the pinning strength and the corresponding Peak Position is higher for the more developed stages of grinding process (corresponding to the number of ground rings). Such behaviour is due to secondary carbides precipitation. Very fine carbides are embedded in the martensite matrix as a result of the primary carbides dissolution at the elevated temperatures during the surface heating. However, over saturation of carbon in the matrix during the consecutive rapid cooling initiates the precipitation of very fine carbides strongly hindering BW motion which in turn results in the higher Peak Positions in the later stages of grinding process (more developed grinding wheel wear) [16].

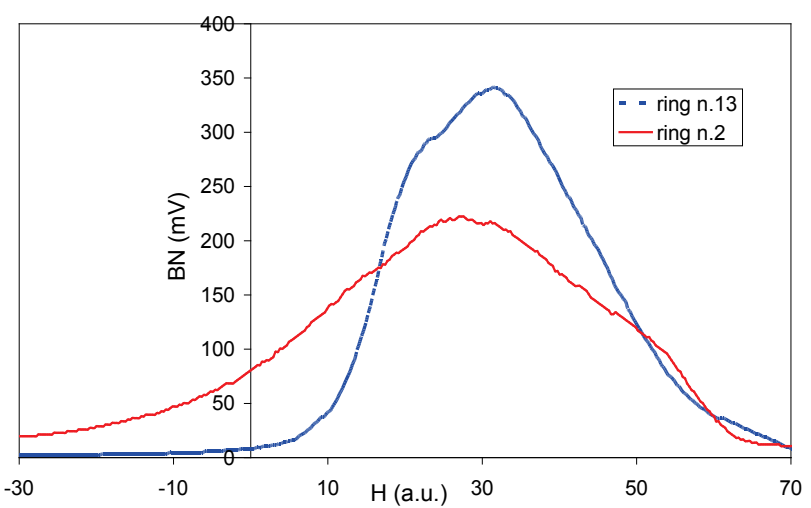

Figure 11 Typical envelope curves extracted from the raw BN signals, high frequency technique, $\mu$ Scan

Fig. 12 shows that Peak Positions parameter progressively increases (with certain saturation at the end of the grinding cycle) with respect to grinding wheel wear and corresponding thermal load of the ground surface. However, instability of grinding and associated strong non homogeneity of ground surfaces integrity during the final phase of grinding cycle increases uncertainty of measurement and therefore evaluation of surface integrity state. Moreover, deformations due to heat treatment regime [17] also contribute to the instable grinding process. Neither the shape of hysteresis loop (extracted from the raw BN signal) nor additional parameters such as permeability, coercive force, remanence, etc. (also extracted from the raw BN signal) provided by standard $\mu$ Scan dataset menu improve detection of various surface integrity states. On the other hand, industrial relevance of the high frequency $\mathrm{BN}$ technique is proved by numerous applications adopted for detection of grinding burn of critical components when the final state of surface damage after finishing is not shadowed by the previous 
roughing damage. Moreover, thermal softening is the dominant mechanism of surface integrity alteration induced by grinding process, while surface re - hardening burn does not occur when usual grinding discipline is maintained.

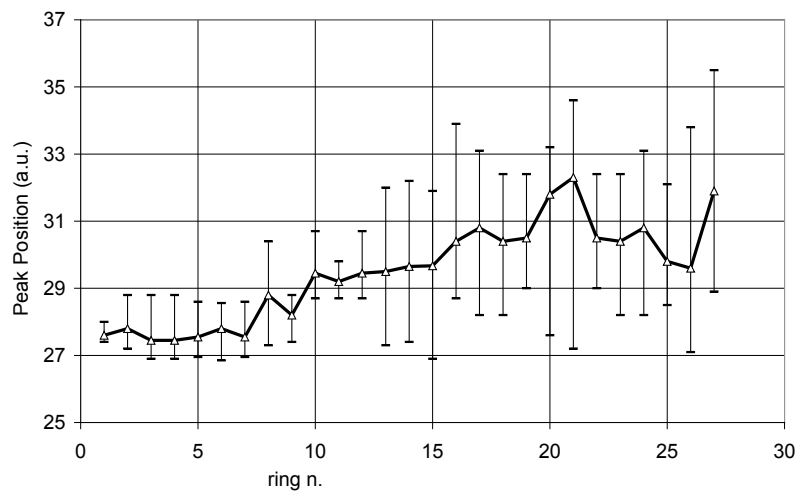

Figure 12 Influence of grinding wheel wear on Peak Position, high frequency technique, $\mu$ Scan

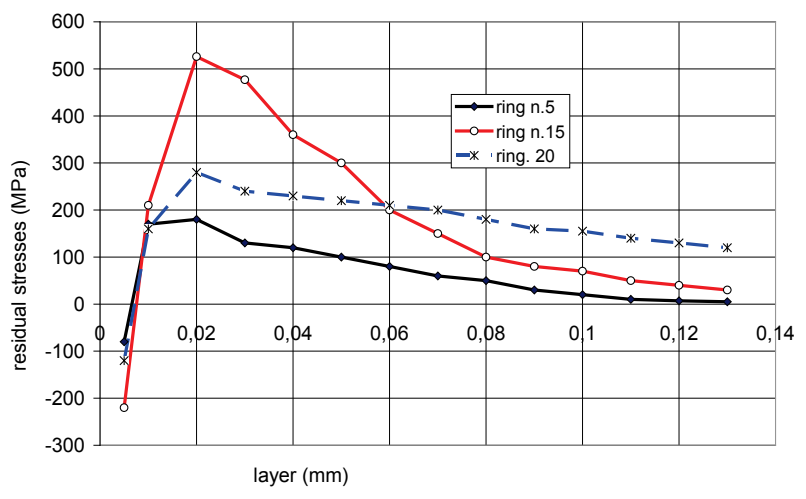

Figure 13 Depth profiles of residual stresses for the different rings

\section{Discussion of results and conclusions}

At the end of this paper the obtained values and different techniques sensitivity should be discussed. It should be reported that the different $\mathrm{BN}$ responses attributed to the high and low frequency magnetization is caused by the different skin - depth. Theoretical evaluation of skin depth is based on the current density $J$ in a conductor which decreases exponentially from its value at the surface $J_{\mathrm{S}}$ according to the depth $d$ from the surface, as follows:

$$
J=J_{\mathrm{S}} e^{-d / \delta}
$$

where $\delta$ is called the skin depth. The skin depth is thus defined as the depth below the surface of the conductor at which the current density has fallen to $1 / e$ (about 0,37 ) of $J_{\mathrm{S}}$. In normal cases it is well approximated as:

$\delta=\sqrt{\frac{2 \rho}{\omega \mu}}$,

where $\rho$ is resistivity of the conductor, $\omega$ angular frequency of current $(2 \pi \times$ frequency $)$ and $\mu$ is absolute magnetic permeability of the conductor. We can derive a practical formula for skin depth as follows:

$$
\delta=\sqrt{\frac{2 \rho}{(2 \pi f)\left(\mu_{o} \mu_{r}\right)}} \approx 503 \sqrt{\frac{\rho}{\mu_{r} f}},
$$

where $\mu_{\mathrm{r}}$ is the relative permeability of the medium and $f$ is the frequency of the current in $\mathrm{Hz}$.

Magnetizing frequency is adjusted as a device parameter and resistivity of inspected structures is usually well known. On the other hand, relative permeability of steels can vary between 60 to $10000 \mathrm{H} / \mathrm{m}$. While permeability of hard steels is low, soft steel gives much higher permeabilities. For this reason, skin depth for different steels can remarkably vary. Fig. 14 illustrates influence of magnetizing frequency and material permeability on the theoretical skin depth obtained by the use of Eq. (3). Permeabilities used for skin depth calculations were found as follows: 60 - hardened steel, 300 - hardened and thermally softened steel, 1000 - soft steel, 5000 - pure Fe. It is visible that calculated skin depths for all magnetizing frequencies highly exceed the maximum found thickness of HAZ (185 $\mu \mathrm{m}$, see Fig. 3). Being so, it can be concluded that the pure theoretical approach based on electromagnetic attenuation could not explain the difference in the different sensitivity between the low and high frequency $\mathrm{BN}$ technique.

Therefore, additional consideration should be discussed. As reported by Moorthy and Shaw [10], the skin depth of BN signal should be considered as the depth of material from where the magnetization process contributes to the detected $\mathrm{BN}$ signal on the surface. $\mathrm{BN}$ signal is a subject of electromagnetic attenuation. Hence, BN signal generated deep below the surface cannot be fully detected on the surface. Except permeability and resistivity of surface as physical constants, the major role is taken by the magnetization range (magnetization voltage $H$ ) and magnetization frequency $f$. When $H$ is small the domain walls can overcome only weak obstacles. When $H$ is large, the $\mathrm{BN}$ signal is generated over wider range and hence it carries more information on the interaction of BW with the different barriers. As Fig. 14 indicates, with increasing magnetization frequency skin depth decreases. This is due to increasing opposition to the rapid change of magnetization as a result of generation of eddy current and other losses induced by non-steady state of magnetization. BN signal measured with higher $H$ and low $f$ gives larger skin depth and $\mathrm{BN}$ signal profiles carries more information on the interaction of BW with pinned sites (weaker and stronger barriers to the BW movement).

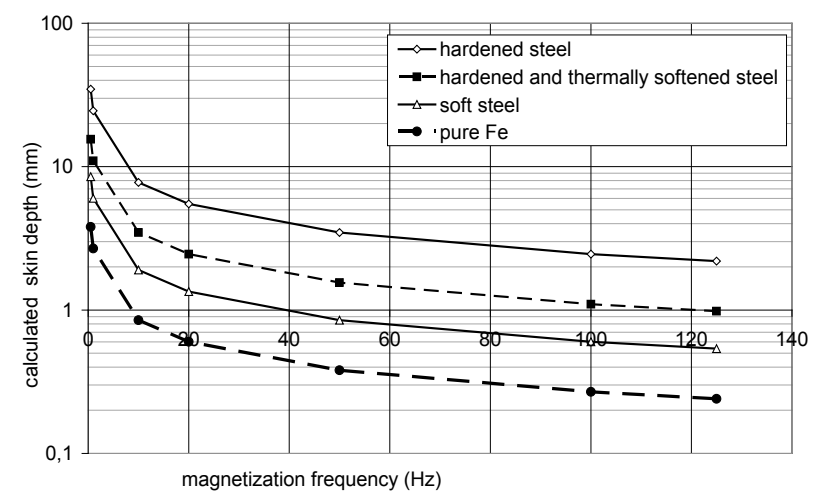

Figure 14 Magnetization frequency versus calculated skin depth 
Being so, higher values and better sensitivity of the low frequency $\mathrm{BN}$ technique for rough grinding at the same magnetizing voltage ( $10 \mathrm{~V}$ for both techniques) is attributed to the higher skin depth and therefore more rich information about BW pulsation in deeper regions since less pronounced attenuation of generated magneto elastic pulses. Tab. 2 indicates that assumed skin depth of the low frequency $\mathrm{BN}$ technique can be expected in several tenths of millimetres while the high frequency BN technique is limited to the low skin depth varying between 20 to $60 \mu \mathrm{m}$.

It can be easily understood that $\mathrm{BN}$ values obtained via the low frequency $\mathrm{BN}$ technique are more sensitive to the extending thickness of HAZ than the high frequency $\mathrm{BN}$ technique since the measured thickness of HAZ highly exceeds the skin depth of the high frequency $\mathrm{BN}$ technique. While the higher values of $\mathrm{BN}$ signal in the transient zone are due to extending thickness of HAZ as well as more pronounced thermal softening in the near surface the higher $\mathrm{BN}$ values indicated by the high frequency technique are only associated with the more pronounced thermal softening in the limited skinned depth.

\section{Acknowledgements}

This project is solved under the financial support of KEGA agency project n. 005ŽU and 009ŽU - 4/2014.

\section{References}

[1] Barkhausen, H. Zwei mit Hilfe der neuen Verstärker entdeckte Erscheinungen. // Physische Zeitschrift. 20, 17(1919), pp. 490-491.

[2] Altpeter, I.; Theiner, W.; R. Becker, R. Eigenspannungsmessunganstal der Güte 22 NiMoCr 37 mit magnetischen und magnetoelastischen Prüfverfahren. // Proceedings of 4th International Conference on NDE in Nuclear Industry, Lindau, (1981), Germany.

[3] Abuku, S.; Cullity, R. D. A Magnetic Method for the Determination of residual Stress. // Exp. Mech., 11, (1971), pp. 217-223. DOI: 10.1007/BF02324218

[4] Cížek, J.; Neslušan, M.; Čilliková, M.; Mičietová, A.; Meliková, O. Modification of steel surfaces induced by turning: non-destructive characterization using Barkhausen noise and positron annihilation. // Journal of Applied Physics D. 47, (2014), pp. 1-17. DOI: 10.1088/00223727/47/44/445301

[5] Stupakov, A.; Neslušan, M.; Perevertov, O. Detection of a milling-induced surface damage by the magnetic Barkhausen noise. // Journal of Magnetism and Magnetic Materials. 410, (2016), pp. 198-209. DOl: 10.1016/j.jmmm.2016.03.036

[6] Biermann, D.; Holtermann, R.; Menzel, A; Schumann, S Modeling and simulation of thermal effect in internal transverse grinding of hardened bearing steel. // CIRP Annals. 65, (2016), pp. 321-324. DOl: 10.1016/j.cirp.2016.04.005

[7] Meyer, D.; Wagner, A., Influence of metalworking fluid additives on the thermal conditions in grinding. // CIRP Annals. 65, (2016), pp. 313-316. DOl: 10.1016/j.cirp.2016.04.016

[8] Heinzel, C.; Meyer, D.; Kolkwitz, B.; Eckebrecht, J. Advanced approach for a demand oriented fluid supply in grinding. // CIRP Annals. 64, (2015), pp. 333-336. DOI: 10.1016/j.cirp.2015.04.009
[9] Aurich, J. C.; Kirsch, B. Improved coolant supply through slotted grinding wheel. // CIRP Annals. 62, (2016), pp. $363-$ 366. DOI: 10.1016/j.cirp.2013.03.071

[10] Moorthy, V. et al. Evaluation of heat treatment and deformation induced changes in material properties in gear steels using magnetic Barkhausen noise analysis. // Proceedings of ICBN 03, Tampere, (2001), Finland.

[11] Moorthy, V.; Shaw, B. A. Magnetic Barkhausen Emission measurement for evaluation of depth of grinding damage. // Proceedings of ICBN 07, Aachen, (2009), Germany.

[12] Mičúch, M.; Čilliková, M.; Neslušan, M.; Mičietová, A. Micromagnetic study of cutting conditions and grinding wheel wear influence on surface integrity. // Manufacturing Technology. 14, (2014), pp. 66-71.

[13] Petru, J.; Zlamal, T.; Čep, R.; Monková, K.; Monka, P. Influence of cutting parameters on heat affected zone after laser cutting. // Tehnicki vjesnik-Technical Gazette. 20, 2(2013), pp. 225-230.

[14] Neslušan, M.; Rosipal, M.; Ochodek, V. Analysis of some aspects of surface integrity after grinding and hard turning trough Barkhausen noise. // Proceedings of ICBN 09, Hejnice, (2011), Czech Republic.

[15] Sorsa, A.; Leviska, K.; Santa Aho, S.; Lepisto, T. Quantitative prediction of residual stresses and hardness in case-hardened steel based on the Barkhausen noise measurement. // NDTE. 46, 1(2012), pp. 100-106. DOl: 10.1016/j.ndteint.2011.11.008

[16] Kejzlar, P. SEM investigation of carbides appearance in bearing steel $100 \mathrm{Cr} 6$ after grinding and hard milling. // Research report, Institute for Nanomaterials, Technical University in Liberec (2015).

[17] Neslušan, M.; Mrkvica, I.; Čep, R.; Kozak, D.; Konderla, R. Deformations after heat treatment and their influence on cutting process. // Tehnicki vjesnik-Technical Gazette. 18, 4(2011), pp. 601-608.

\section{Authors' addresses}

Anna Mičietová, Prof., PhD, MSc.

Faculty of Mechanical Engineering, University of Žilina, Univerzitná 1, 01026 Žilina, Slovak Republic

E-mail: anna.micietova@fstroj.uniza.sk

Miroslav Neslušan, Prof., Dr., MSc.

Faculty of Mechanical Engineering, University of Žilina, Univerzitná 1, 01026 Žilina, Slovak Republic E-mail: miroslav.neslusan@ffstroj.uniza.sk

Robert Čep, Assoc. Prof., PhD, MSc.

Faculty of Mechanical Engineering,

Technical University of Ostrava,

17. listopadu 15/2172, 708 33, Czech Republic

E-mail: robert.cep@vsb.cz

\section{Vladislav Ochodek, MSc.}

Faculty of Mechanical Engineering,

Technical University of Ostrava,

17. listopadu 15/2172, 708 33, Czech Republic

E-mail: vladislav.ochodek@vsb.cz

Branislav Mičieta, Prof., PhD, MSc.

Faculty of Mechanical Engineering, University of Žilina, Univerzitná 1, 01026 Žilina, Slovak Republic

E-mail: branislav.micieta@fstroj.uniza.sk

Marek Pagáč, MSc.

Faculty of Mechanical Engineering, Technical University of Ostrava,

17. listopadu 15/2172, 708 33, Czech Republic

E-mail: marek.pagac@vsb.cz 